\title{
Correction to: Telomere length variation does not correspond with the growth disturbances in the rainbow trout (Oncorhynchus mykiss)
}

\author{
Ligia Panasiak $^{1} \cdot$ Karolina Szubert $^{2} \cdot$ Marcin Polonis $^{1} \cdot$ Konrad Ocalewicz $^{1}$
}

Published online: 23 November 2021

(c) The Author(s), under exclusive licence to Institute of Plant Genetics Polish Academy of Sciences 2021

Correction to: Journal of Applied Genetics (2021) https://doi.org/10.1007/s13353-021-00669-6

Originally, part of the Figure 2 is missing in the published paper. The figure is now replaced with the correct image.

The original article has been corrected.

Publisher's note Springer Nature remains neutral with regard to jurisdictional claims in published maps and institutional affiliations.

The original article can be found online at https://doi.org/10.1007/ s13353-021-00669-6

Konrad Ocalewicz

konrad.ocalewicz@ug.edu.pl

1 Department of Marine Biology and Ecology, Institute of Oceanography, University of Gdansk, M. Piłsudskiego 46 Av, 81378 Gdynia, Poland

2 Department of Marine Biotechnology, Institute of Oceanography, University of Gdansk, M. Piłsudskiego 46 Av, 81-378 Gdynia, Poland 